\title{
Role of Polymer in Weeding and Seeding Machinery in Agriculture Rice Mechanization
}

\author{
M. Mohan \\ CIAE- Reg. Centre \\ Coimbatore, India
}

\author{
G. Sundararaj \\ PSG College of Tech. \\ Coimbatore, India
}

\author{
Ravindra Naik \\ CIAE- Reg. Centre \\ Coimbatore, India
}

\author{
A.R. Soman \\ Govt. Engg. College, \\ Thrissur, India
}

\begin{abstract}
In agricultural farm machinery, polymers are widely used for many applications. In recent years many agricultural farm implements are adopting polymer based plastic parts like seed dill ferule roller, weeding equipment, star wheel of harvester, vegetable planter hopper, zero till drill flute, animal yoke, maize sheller, diary vessels etc as a step towards value engineering. By varying the synthetic blend component and its miscibility with starch, the morphology and hence the properties can be regulated easily and efficiently. Blends containing thermoplastic starch (non crystalline starch) may be blended or grafted with biodegradable polyesters, such as polycaprolactone, to increase flexibility and resistance to moisture. Blends mainly formed into films and sheets, that are used for foaming and injection molding. By mixing thermoplastic starch with cellulose derivatives, rigid and dimensionally stable injection molded articles result. Seeding and weeding in paddy is an essential component in paddy production. There are many models of seeders and single row cono weeders available in the market which are being used for mechanized seeding and weeding operation. These are basically made with Mild Steel which has certain disadvantages in terms of machinability, reproducibility, weight, life, appearance etc. An improved manually operated 8-row drum seeder (plastic moulded) for direct sowing of pre-germinated paddy for wetlands and plastic moulded cono weeder developed was evaluated for its performance in various farmers field. It was observed that the cost of production of plastic moulded eight row drum seeder and plastic moulded cones for cono weeder was almost on par to that of these equipment made with MS sheet. Field studies revealed that plastic moulded seeder and cono weeder recorded higher field capacity, seeding/ weeding index and performance index over implement made of MS, with lower working force and plant damage. The ergonomic study revealed that heart beat/min, $\mathrm{VO}_{2} / \mathrm{min}$, ODR score, body part discomfort score, OCR as $\mathrm{VO}_{2}$ max, per cent of plastic moulded equipment was found better over metallic model of equipment. This clearly gave an indication that there is a scope for substitution of MS material by polymers in rice mechanization. This paper deals with production process and performances evaluation of plastic moulded cono weeder for wet land paddy production.
\end{abstract}

Key words: Rice mechanization, Polymer, cono weeder, drum seeder, molding process, Ergonomics studies.

\section{INTRODUCTION:}

The average productivity of rice in India, at present, is $2.2 \mathrm{t} / \mathrm{ha}$, which is far below the global average of $2.7 \mathrm{t} / \mathrm{ha}$. The productivity of rice is higher than that of Thailand and Pakistan but much lesser than that of Japan, China, Vietnam and Indonesia (Anon., 2011). Transplanting of paddy in puddled field is generally preferred over dry sowing of seed due to severe problems of weeds. There are different types of paddy seeder are available with mild steel and aluminum material 
used in the part of drum which is carrying the paddy seed. The mild steel drum seeder while using day by day in wet land easily occur corrosion and reduced reliability and life of the seeder. Now a days paddy seeder are improved and modified drum with hyperboloid shaped with Medium Density Poly Urethane material used (Fig.1). Weeding is an important practice to be carried out during the initial stages of crop growth especially for controlling the weeds competing with the crop, stirring the soil for aerating the crop root zones and for burying the weeds in to the soil (Kwesi and De Datta, 1991). In India, farmers mainly follow manual hand weeding and chemical weeding. The manual weeding, which takes about 20 per cent of labour requirement in paddy cultivation is expensive and drudgeries operation (Sucheta Singh and Oliver Hensel 2012). The operation of weeding is usually performed manually with the use of bare hands/ traditional hand tools in bending position, inducing back pain. With the scarcity of labour mechanical weeding is the only solution as it is an environmentally safe alternative to herbicides for weed control. Availability of skilled labour is also scarce. To obviate this mechanical weeding is the only solution. At present there are many weeders being used in paddy. Among these, the cono weeder is the most effective and popular (Fig.2). The normal cono weeders available in the markets have the cones made of Mild Steel (MS) based on International Rice Research Institute, Philippines design. Since the cones of the cono weeders are in constant contact with the soil, the rolling resistance by the wet soil on the weeder surface creates strain on the operator while pushing this equipment. Also due to constant contact with the soil, there is a tendency to develop rust and hence hinder in the smooth operation and reduce the life of the cono weeder. Since cone is the part which comes into contact with the soil, an effort was made to use an alternative material for the cone to reduce the force required to push the weeder. Further, it was found that fabrication of cones was a tedious process and time consuming process. To make production process faster and to maintain interchangeability of parts, a production process was developed jointly by Central Institute of Agricultural Engineering, Regional Centre, in collaboration with M/s KSNM Marketing, Coimbatore, a leading manufacturer of cono weeder (Rvindra Naik et.al., 2013 \& Annamalai et.al. 2012).

\section{PRINCIPLE OF CONO WEEDER:}

The cono weeder is used for uprooting and burying weeds in between standing rows of rice in wetlands with the help of a set of lugs in the conical rotor/cones due to its pull and push operations. A pair of cones are placed one behind the other in an offset manner. A long handle is provided for the operation of the unit. A float is provided ahead of the pair of cones which gives buoyancy effect and prevents sinking of the unit into the wet soil during operation. During the forward movement of the operator, the weeder creates horizontal back and forth movement in the top $3 \mathrm{~cm}$ layer of the soil and the weeds are uprooted and buried in a single pass. It disturbs the topsoil and increases the aeration to the root zone. This helps in better root growth which in turn leads to better physiological growth, greater tillering and higher yield. A thin film of water is a prerequisite for effective operation of the cono weeder. If the soil is too dry, the cono weeder rolls over the soil surface without uprooting and burying the weeds. Cono weeder is also used to mulch the green manuring plants which are grown in the intra row spacing in paddy field. Generally, first weeding is done within 15-20 days of planting seedlings and second weeding is taken up again after 15 days. Third and fourth weeding before onset of flowering can be also taken up for the increase in yield (Ravindra Naik et.al., 2013)

\section{DEVELOPMENT OF PRODUCTION PROCESS OF PLASTIC MOULDED CONO WEEDER:}

To use an alternate material for the cone, polypropylene impact copolymer, manufactured by copolymerising propylene was attempted. The propylene elastomeric phase in the polypropylene impact copolymer improves the impact strength of the products, and more importantly this improved impact strength is retained even at sub-zero temperatures. The medium melt flow characteristic of copolymer grade MI1530 is especially suited for 
injection-moulded components in the industrial sector. The grade possesses good toughness and the articles moulded can withstand a continuous. service temperature of up to $90^{\circ} \mathrm{C}$ This grade meets with the requirements of Indian Standard IS: 10910 on "Specifications for Polypropylene and its copolymers for its safe use in contact with foodstuffs, pharmaceuticals and drinking water". The grade also complies with FDA regulation: CFR TITLE $21-177.1520$, on olefin polymers. The details of production process of plastic moulded cones are given in Fig 3 .

\section{RESULT AND DISCUSSION}

\subsection{Comparison between M.S. sheet cone v/s plastic cone with M.S. sheet lugs:}

From the Table 1, it is observed that the cost of pproduction of plastic moulded cones for improved cono weeder is Rs $280 /$ cone, which is only slightly higher than m.s. sheet cones (Rs 260/cone). But there are several advantages by adopting the process for production of plastic moulded cones. It is seen that the production capacity per person per day has increased from 4 to 50 cones. Apart from this it is easy to maintain the quality of production, and the inter changeability of the component can also be achieved. The weight of the weeder has also been reduced from 7.5 to $6.1 \mathrm{~kg}$ (by 19 per cent). (Annamalai et.al., 2012, Ravindra Naik et. Al., 2013)

\subsection{Performance evaluation of the cono weeder:}

The performance evaluation of the cono weeder with plastic moulded cones (Fig. 1) in comparison with commercial model of cono weeder was taken up at lowland paddy fields in the standing crop of ADT 43 variety at Bhavanisagar, Tamil Nadu, India. During the experiment, effective field capacity, weeding index, plant damage, and performance index were determined Table. 2 .

\subsection{Ergonomical evaluation:}

Ergonomical evaluation was carried out on selected female workers for assessing their suitability in terms of the following (Fig .4).

\section{(i) Heart rate and oxygen consumption} rate:

These are relevant parameters for assessing the human energy for performing various operations (Gite and Singh, 1997)

\section{(ii) Energy cost of operation:}

The energy costs of operation of the selected weeders were computed by multiplying the oxygen consumed by the subject during the trial period with the calorific value of oxygen as $20.88 \mathrm{~kJ} / \mathrm{l}$ (Nag and Dutt, 1979)

\section{(iii) Acceptable work load:}

The acceptable workload (AWL) for Indian workers was the work consuming 35 per cent of $\mathrm{VO}_{2} \max$ (Gite and Singh, 1997 and Muthamil Selvan et.al., 2010).

\section{(iv)Limit of continuous performance $(L C P)$ :}

The extent to which a person may increase his work rate depends in part on how much he can increase his heart rate from resting level to his maximum level, because the increase in heart rate plays a major role in increasing the cardiac output from rest to maximal work (Rodahl, 1989 ). To have a meaningful comparison of physiological response, $\Delta H$ values (Increase over resting values) for heart rate (work pulse) was calculated (Tewari. et.al., 1991).

\section{(v) Overall discomfort rating $(O D R)$ :}

For the assessment of overall discomfort rating a 10 - point psychophysical rating scale $(0$ no discomfort, 10 - extreme discomfort) was used which is an adoption of Corlett and Bishop (1976) technique.

\section{Conclusion:}

An injection moulding process using polypropylene copolymer (PPCP) for making the cones for conoweeder has been developed. The blades are of m.s.sheet and are inserted into the 


\section{International Journal of Science and Engineering Applications Special Issue NCRTAM ISSN-2319-7560 (Online)}

moulded die before starting of moulding process. Field evaluation study reported that the modified cono weeder recorded better field performance, enhanced the comfort with considerable reduction in heartbeat, oxygen consumption, acceptable work load, limit of continuous performance, overall discomfort rating, body part discomfort rating. The production process had higher output per person;

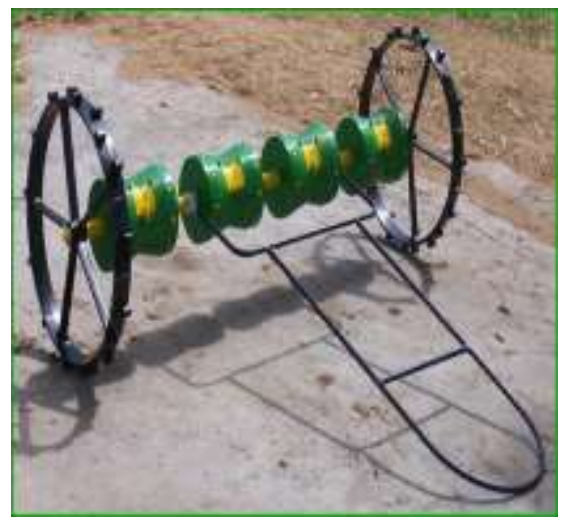

Figure. 1. Eight row paddy seeder.

(Ccourtesy: M/s. KSNM Marketing, Coimbatore, India)

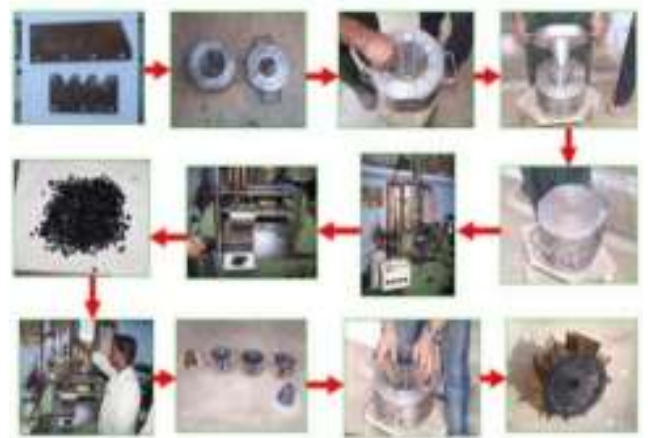

Figure 3. Production process of plastic moulded Cono weeder ( $\backslash$ Courtesy M/s. KSNM Marketing, Coimbatore, India) interchangeability of parts was possible; less labour dependent and better production quality could be maintained. The study concluded that there is a tremendous scope to replace the existing m.s cones with polypropylene impact copolymer material by adopting the injection moulding production process.

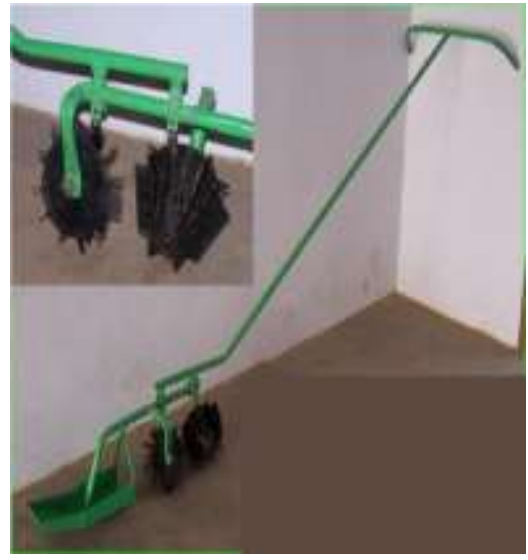

Figure 2, Plastic moulded cono weeder. (Courtesy: M/s. KSNM Marketing, Coimbatore, India)

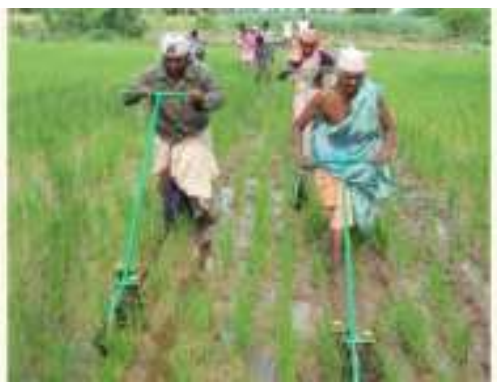

Figure. 4, Ergonomic evaluation of plastic moulded cono weeder 
Table 1. Comparison between m.s. sheet cone v/s Plastic cone with m.s sheet lugs (Annamalai, et.al 2012)

\begin{tabular}{|c|c|c|}
\hline \multirow[t]{2}{*}{ Description } & Commercial model & Improved model \\
\hline & M.S Sheet cone & Plastic cone + M.S. Sheet lugs \\
\hline Material used & m.s. sheet $(1.5 \mathrm{~mm}): 1100 \mathrm{~g}$ & $\begin{array}{l}\text { Polypropylene : } 750 \mathrm{~g} \\
\text { m.s. sheet }(2 \mathrm{~mm}): 750 \mathrm{~g}\end{array}$ \\
\hline M.S Welding cost & $\begin{array}{l}\text { Rs } 120 \text { ( } 4 \text { cones/ } \\
\text { day/welder) }\end{array}$ & NIL \\
\hline Injection moulding cost & NIL & Rs 60/ cone \\
\hline Material cost & Rs $140 /$ rotor & $\begin{array}{l}\text { Polypropylene : Rs } 120 \\
\text { M.S. Sheet (2mm): Rs } 100 \\
\text { Total : Rs } 220\end{array}$ \\
\hline Total cost & Rs 260/cone & Rs $280 /$ cone \\
\hline Output/day/ worker & Four cones & Fifty cones \\
\hline Major Differences & $\begin{array}{l}\text { 1. Production rate is less } \\
\text { 2. No consistency in quality } \\
\text { 3. More labour dependent }\end{array}$ & $\begin{array}{l}\text { 1.More pieces can be manufactured per unit time } \\
\text { 2. Quality can be maintained } \\
\text { 3. Life of cones is expected to increase } \\
\text { 4.Less labour dependent } \\
\text { 5. Interchangeability of the component }\end{array}$ \\
\hline
\end{tabular}

Table 2. Field performance of cono weeders under investigation.(Ravindra Naik et.al., 2013)

\begin{tabular}{|l|l|l|l|}
\hline \multicolumn{2}{|c|}{ Commercial weeder } & $\begin{array}{l}\text { Cono weeder with } \\
\text { plastic moulded cones }\end{array}$ & $\begin{array}{l}\text { Difference over } \\
\text { commercial weeder, } \\
\text { per cent }\end{array}$ \\
\hline $\begin{array}{l}\text { Effective Field capacity }, \\
\mathrm{m}^{2} / \mathrm{h}\end{array}$ & 190.0 & 265.00 & 28.30 \\
\hline Weeding index, per cent & 75.2 & 81.1 & 7.04 \\
\hline Pushing Force, N & 43.3 & 37.50 & $-(13.39)$ \\
\hline Plant damage, per cent & 6.1 & 5.90 & $-(3.27)$ \\
\hline Performance Index & 1358.1 & 2031.90 & 49.61 \\
\hline Weight, $\mathrm{kg}$ & 7.5 & 6.1 & $-(18.6)$ \\
\hline
\end{tabular}


Table3. Ergonomic evaluation of operator using two models of cono weeders (Ravindra Naik et.al., 2013)

\begin{tabular}{|l|l|l|l|}
\hline \multicolumn{2}{|c|}{ Type of weeder } & $\begin{array}{l}\text { Difference over } \\
\text { commercial weeder, } \\
\text { per cent }\end{array}$ \\
\hline & $\begin{array}{l}\text { Commercial } \\
\text { cono weeder }\end{array}$ & $\begin{array}{l}\text { Cono weeder with } \\
\text { plastic mouded cones }\end{array}$ & $-(20.43)$ \\
\hline Heart beat/min & 162 & 128.80 & $-(12.41)$ \\
\hline $\mathrm{VO}_{2} / \mathrm{min}$ & 1.45 & 1.27 & $-(11.29)$ \\
\hline ODR Score & 6.2 & 5.50 & $-(33.14)$ \\
\hline $\begin{array}{l}\text { Body part discomfort } \\
\text { score }\end{array}$ & 39.4 & 26.34 & $-(8.63)$ \\
\hline $\begin{array}{l}\text { OCR as } \mathrm{VO}_{2} \text { max, per } \\
\text { cent }\end{array}$ & 83.4 & 76.2 & \\
\hline Energy grade & Heavy & Heavy & $-(18.60)$ \\
\hline Rest pause, min & 12.9 & 10.5 & \\
\hline
\end{tabular}

\section{REFERENCES:}

[1] Anon., 2011. Vision 2030 document of Central Rice Research Institute, Cuttack.

[2] Kwesi A..K . and De Datta, S.K. 1991.Handbook of weed control in Rice. IRRI. International Rice Research Institute, P.O Box 933, 1099, Manila, Philippines. ISBN 971-22-0020-05.

[3] Gite,L.P.andSingh,G.1997. Ergonomics in agricultural and allied activities in India. Technical Bulletin No. CIAE

[4] Nag, P.K and Dutt P. 1979. Effectiveness of some simple agricultural weeders with reference to physiological responses. Journal of Human Ergology, 8: 13-21.

[5] Muthamil Selvan, M. Kathirvel, K, Annamalai SJK and Thambidurai. 2010. Ergonomic intervention in Cono weeder. National Seminar conducted by ISAE - AP Chapter. September $24-25^{\text {th }}, 2010$ at Tirupati ISAE - APC10/FMP-AB/06. pp 3234.

[6] Rodahl, K.1989. The Physiology of work London. Taylor and Francis. $290 \mathrm{p}$.

[7] Tewari V.K., Datta R.K and Murthy A.S..1991. Evaluation of three manually operated weeding devices. Applied Ergonomics,22(2):3-

[8] Sucheta Singh and Oliver Hensel. 2012 On farm research on transplanting paddy: A"best-Bet" Prototype for drudgery reduction, International Journal of Agriculture Research and Review Vol., 2(4), 2012, ISSN 2228-7973 @ 2012 ECISI Journal./

[9] Annamalai SJK, Madeswaran CV, Ravindra zNaik and Muthamil Selvan,, 2012. Development of Production process for improved single row cono weeder (manual) by injection moulding for wet land paddy. Agricultural Engineering Today, 36(4); pp 12-17.

[10] Ravindra Naik, SJK Annamalai, C.V. Madeswaran and M. Muthamil Selvan 2013.Mass production improved plastic moulded single row cono weer by injection moulding. Presented at the ARRW Golden Jubilee International Symposium - 2013 entitled sustainable rice productions and livelihood security: challenges and opportunities organized by Association of Rice Research Workers, CRRI, Cuttack from the $2^{\text {nd }}$ to $5^{\text {th }}$ of march 2013 . AbstractA339. 